\title{
Endovascular Treatment of Wide-Neck Anterior Communicating Artery Aneurysms Using WEB-DL and WEB-SL: Short-Term Results in a Multicenter Study
}

D.N. Gherasim, B. Gory, R. Sivan-Hoffmann, L. Pierot, H. Raoult, J.-Y. Gauvrit, H. Desal, X. Barreau, D. Herbreteau, R. Riva, F. Ambesi Impiombato, X. Armoiry, and F. Turjman

\begin{abstract}
BACKGROUND AND PURPOSE: Endovascular treatment of wide-neck anterior communicating artery aneurysms can often be challenging. The Woven EndoBridge (WEB) device is a recently developed intrasaccular flow disrupter dedicated to endovascular treatment of intracranial aneurysms. The aim of this study was to investigate the feasibility, safety, and efficacy of the WEB Dual-Layer and WEB Single-Layer devices for the treatment of wide-neck anterior communicating artery aneurysms.
\end{abstract}

MATERIALS AND METHODS: Patients with anterior communicating artery aneurysms treated with the WEB device between June 2013 and March 2014 in 5 French centers were analyzed. Procedural success, technical complications, clinical outcome at 1 month, and immediate and 3- to 6-month angiographic follow-up results were analyzed.

RESULTS: Ten patients with unruptured anterior communicating artery aneurysms with a mean neck diameter of $5.4 \mathrm{~mm}$ were treated with the WEB. Treatment failed in 3 of the 10 aneurysms without further clinical complications. One patient developed a procedural thromboembolic event, and the other 6 had normal neurologic examination findings at 1-month follow-up. Immediate anatomic outcome evaluation showed adequate occlusion (total occlusion or neck remnant) in 6 of 7 patients. Angiographic control was obtained in all patients, including 6 adequate aneurysm occlusions ( 3 complete occlusions and 3 neck remnants) at short-term follow-up.

CONCLUSIONS: In our small series, treatment of wide-neck anterior communicating artery aneurysms with the WEB device was feasible and safe. However, patient selection based on the aneurysm and initial angiographic findings in the parent artery is important due to the limitations of the WEB device navigation.

ABBREVIATIONS: WEB $=$ Woven EndoBridge; WEB-DL $=$ WEB Dual-Layer; WEB-SL $=$ WEB Single-Layer

C oiling of intracranial aneurysms is now a well-established endovascular treatment option. ${ }^{1,2}$ Nevertheless, in cases of wide-neck aneurysms, coiling alone has often been proved unsuitable. Balloon-assisted and stent-assisted coiling may be therapeutic options. ${ }^{3-5}$ However, low rates of initial angiographic occlusion and high rates of recurrence are reported in such situations. ${ }^{5-7}$ In

Received July 11, 2014; accepted after revision December 14.

From the Department of Interventional Neuroradiology (D.N.G., B.G., R.S.-H., F.A.I., R.R., F.T.) and Direction de la Recherche Clinique et de l'Innovation (X.A.), Hôpital Neurologique Pierre Wertheimer, Hospices Civils de Lyon, Lyon, France; Department of Radiology (L.P.), Hôpital Maison Blanche, Reims, France; Department of Neuroradiology (H.R., J.-Y.G), Centre Hospitalier Universitaire Rennes, Rennes, France; Department of Neuroradiology (H.D.), Centre Hospitalier Universitaire Nantes, Nantes, France; Department of Neuroradiology (X.B.), Pellegrin Hospital, Bordeaux, France; and Department of Neuroradiology (D.H.), Centre Hospitalier Universitaire Tours, Tours, France.

D.N.G. and B.G. contributed equally to this work.

Please address correspondence to Benjamin Gory, MD, MSc, Department of Interventional Neuroradiology, Hôpital Neurologique Pierre Wertheimer, Hospices Civils de Lyon, 59 Bd Pinel, 69677 Bron, France; e-mail: benjamin.gory@chu-lyon.fr http://dx.doi.org/10.3174/ajnr.A4282 addition, bifurcation aneurysms often require an X- or Y-configuration double-stent treatment technique that carries a higher rate of procedural complications ${ }^{8-13}$ in addition to the complications linked to the mandatory use of dual antiplatelet therapy. ${ }^{11-13}$

The Woven EndoBridge (WEB) aneurysm embolization system (Sequent Medical, Aliso Viejo, California) is a recently developed intrasaccular flow disruptor dedicated to intracranial wide-neck aneurysm management; to date, WEB Dual-Layer (WEB-DL) feasibility, safety, and short-term angiographic findings have only been reported in a few studies, mostly in aneurysms of the middle cerebral artery, while its feasibility and results in treatment of anterior communicating artery aneurysms are not well-known. ${ }^{14-18}$ The characteristics of the WEB device combining a large-diameter microcatheter and a relatively stiff device may hamper its placement in this location.

The goal of this study was to analyze the feasibility, safety, and efficacy of WEB-DL and WEB Single-Layer (WEB-SL) flow disruptors for the treatment of wide-neck anterior communicating artery aneurysms. 


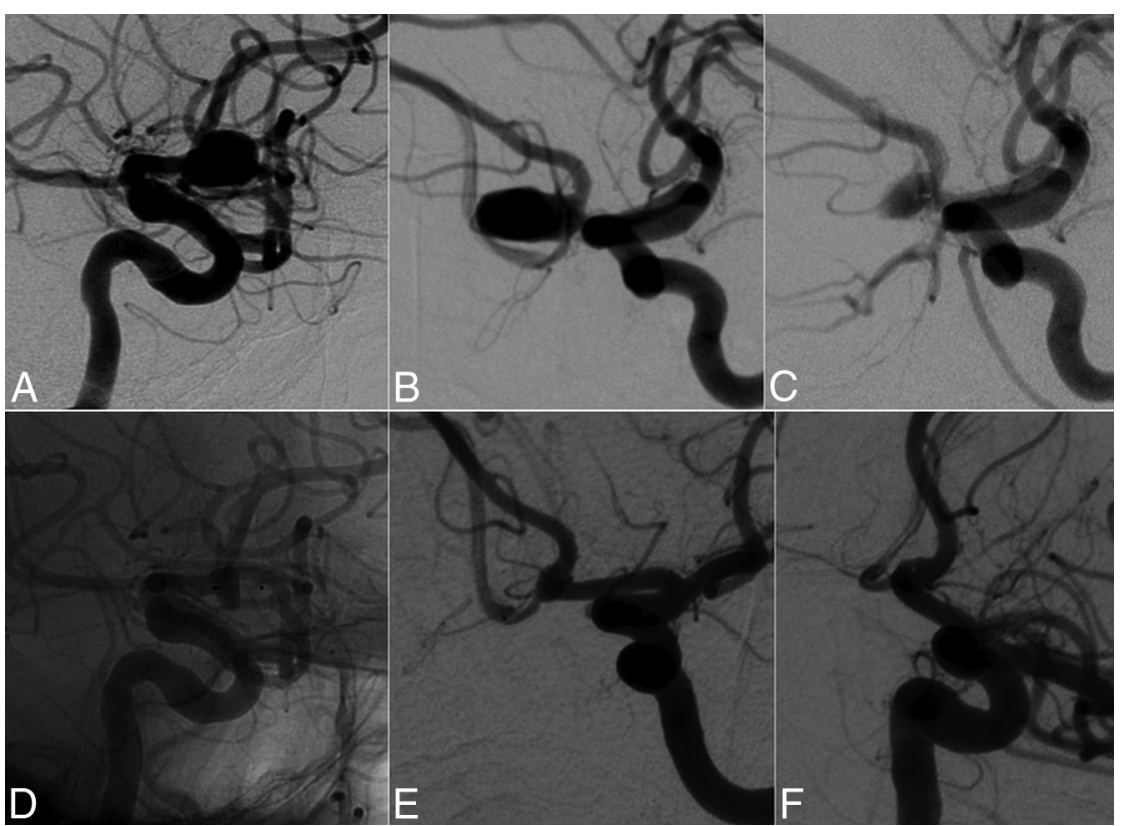

FIG 1. A 65-year-old man with an unruptured anterior communicating artery aneurysm. $A$ and $B$, Angiography shows a wide-neck anterior communicating artery aneurysm. $C$, End-procedure angiography shows satisfactory occlusion of the aneurysm with a neck remnant. $D$, Unsubstracted lateral view shows the WEB device. $E$ and $F$, Follow-up angiography at 6 months shows complete aneurysm occlusion.

\section{MATERIALS AND METHODS \\ Population}

Between June 2013 and March 2014, patients with anterior communicating artery aneurysms in 5 French centers were treated by using a WEB device. Patient selection was made by the interventional neuroradiologists of each center according to the aneurysm location, size, and neck diameter. Patients were selected for the WEB device when their wide-neck aneurysms necessitated an adjunctive technique such as Y-stent placement. In these situations, we chose to use an intrasaccular device rather than other techniques. Ethics committee approval from each center was obtained for this prospective study. All patients signed an informed consent.

\section{Characteristics of the WEB Device}

We used 2 types of WEB devices: the DL and SL. The WEB-DL is composed of inner and outer nitinol braids held together by proximal, middle, and distal radiopaque markers, thereby obtaining 2 separate compartments, 1 distal and 1 proximal (Fig $1 A$ ). The WEB-SL is composed of only 1 nitinol braid held together by 2 markers (Fig 1B). The WEB device is deployed in a manner similar to that of endovascular coils via the use of $a \geq 0.027$ inch internal-diameter microcatheter. The detachment system is electrothermal and instantaneous. The WEB device is CEapproved for use in unruptured and ruptured intracranial aneurysms.

\section{Endovascular Procedure}

All procedures were performed with the patient under general anesthesia and systemic heparinization. Unilateral femoral access was performed, and the tip of the long sheath was placed in the left or right common carotid artery. A coaxial system was assembled, and the aneurysm was catheterized with a Rebar 27 (Covidien, Irvine, California), Marksman 27 (Covidien), or DAC 038 (Concentric Medical, Mountain View, California). The WEB device chosen according to the aneurysm diameters was then deployed into the sac. After deployment, a control angiogram was performed to check the position of the device in the aneurysm. If the position or the size was not satisfactory, the device was then resheathed and repositioned or resheathed and replaced by another, more suitable device.

\section{Outcome Evaluation}

Clinical outcomes were assessed at discharge and 1 month by using the modified Rankin Scale. ${ }^{19}$ Morbidity was defined as an mRS score of 2-5.

Angiographic images were obtained in anteroposterior, lateral, and working projections before, immediately after treatment, and at 3 or 6 months' follow-up according to the center. A simplified 3-point Raymond scale (total occlusion, neck remnant, aneurysm remnant) was used to assess the results of the procedure. ${ }^{6}$

\section{RESULTS}

Ten patients ( 4 women and 6 men; mean age, 59.3 years) with unruptured anterior communicating artery aneurysms were included. The mean width size was $6.2 \mathrm{~mm}$ (range, 3.5-8.1 mm), the mean dome size was $5.8 \mathrm{~mm}$ (range, $3.8-8.2-\mathrm{mm}$ ), and mean neck size was $5.4 \mathrm{~mm}$ (range, 3.6-8-mm) (Table 1). Successful deployment of the WEB was obtained in 7 patients (with 2 WEB-DLs and 5 WEB-SLs). In all successful cases, the aneurysms were treated with a single device.

\section{Treatment Failure}

In 3 patients (patients 1, 4, and 5), WEB deployment failed. In case 1 , the device could not be advanced beyond the carotid bifurcation due to unfavorable vascular anatomy conditions, which led to instability of the microcatheter; the aneurysm was then successfully coiled. In case 4, correct WEB deployment was achieved, but on control angiograms, suboptimal positioning of the device was seen with its base protruding through the neck of the aneurysm inside the parent artery. A second, $6 \times 3 \mathrm{~mm}$, WEB-DL device was than deployed, again with suboptimal positioning. The aneurysm was then treated with a balloon-assisted coiling technique. In case 5, WEB-deployment failure occurred due to difficult microcatheter navigation through the A1 segment of the anterior cerebral artery; the aneurysm was later coiled successfully.

\section{Procedural Complications}

No intraoperative aneurysm rupture was observed during WEB deployment. In 1 patient (patient 2), the base of the WEB protruded into the lumen of the left A2 segment through the aneu- 
Table 1: Clinical presentation and aneurysm characteristics in 10 patients with 10 anterior communicating artery aneurysms

\begin{tabular}{|c|c|c|c|c|c|c|}
\hline \multirow[b]{2}{*}{ No. } & \multirow{2}{*}{$\begin{array}{l}\text { Age (yr) } \\
\text { Sex }\end{array}$} & \multirow{2}{*}{$\begin{array}{c}\text { Aneurysm } \\
\text { Status }\end{array}$} & \multicolumn{3}{|c|}{ Aneurysm Characteristics } & \multirow{2}{*}{$\begin{array}{c}\text { WEB Size }(\mathrm{mm}) \text {, } \\
\text { Type }\end{array}$} \\
\hline & & & Neck (mm) & Width (mm) & Dome (mm) & \\
\hline 1 & $56, \mathrm{~F}$ & Unruptured & 6.6 & 6.3 & 6.9 & $7 \times 5, \mathrm{DL}$ (failure) \\
\hline 2 & $56, M$ & Unruptured & 8 & 8.1 & 5.6 & $8 \times 5, \mathrm{DL}$ \\
\hline 3 & $65, F$ & Unruptured & 5.6 & 6.2 & 5.1 & $7 \times 4, \mathrm{DL}$ \\
\hline 4 & $54, \mathrm{~F}$ & Unruptured & 4.8 & 6 & 4 & $6 \times 3, \mathrm{DL}$ (failure) \\
\hline 5 & $52, M$ & Unruptured & 3.6 & 3.5 & 3.8 & $4 \times 3$, SL (failure) \\
\hline 6 & $56, M$ & Unruptured & 3.9 & 6.7 & 6.4 & $7 \times 5, S L$ \\
\hline 7 & $65, M$ & Unruptured & 5.3 & 5.9 & 8.2 & $7 \times 6, S L$ \\
\hline 8 & $68, F$ & Unruptured & 5.4 & 6.5 & 5.3 & $7 \times 3, S L$ \\
\hline 9 & $75, M$ & Unruptured & 5.4 & 7.5 & 6.3 & $8 \times 4, S L$ \\
\hline 10 & $46, M$ & Unruptured & 5.4 & 5.5 & 6.1 & $7 \times 5, S L$ \\
\hline
\end{tabular}

Table 2: Clinical and anatomic outcomes

\begin{tabular}{|c|c|c|c|c|c|}
\hline \multirow[b]{2}{*}{ No. } & \multicolumn{2}{|l|}{ Clinical } & \multicolumn{3}{|c|}{ Anatomic } \\
\hline & Initial Symptoms & $\begin{array}{c}\mathrm{mRS} \text { at } \\
1 \mathrm{Mo}\end{array}$ & Immediate & $\begin{array}{l}\text { Time } \\
\text { (mo) }\end{array}$ & Short-Term \\
\hline 1 & Headaches & 0 & WEB failure & - & - \\
\hline 2 & Asymptomatic & 1 & Neck remnant & 3 & Aneurysm remnant \\
\hline 3 & Asymptomatic & 0 & Complete occlusion & 3 & Complete occlusion \\
\hline 4 & Asymptomatic & 0 & WEB failure & - & - \\
\hline 5 & Headaches & 0 & WEB failure & - & - \\
\hline 6 & Asymptomatic & 0 & Aneurysm remnant & 6 & Neck remnant \\
\hline 7 & Headaches & 0 & Neck remnant & 6 & Complete occlusion \\
\hline 8 & Seizures & 0 & Complete occlusion & & Neck remnant \\
\hline 9 & Severe headaches & 0 & Neck remnant & 3 & Complete occlusion \\
\hline 10 & Vertigo & 0 & Neck remnant & 6 & Neck remnant \\
\hline
\end{tabular}
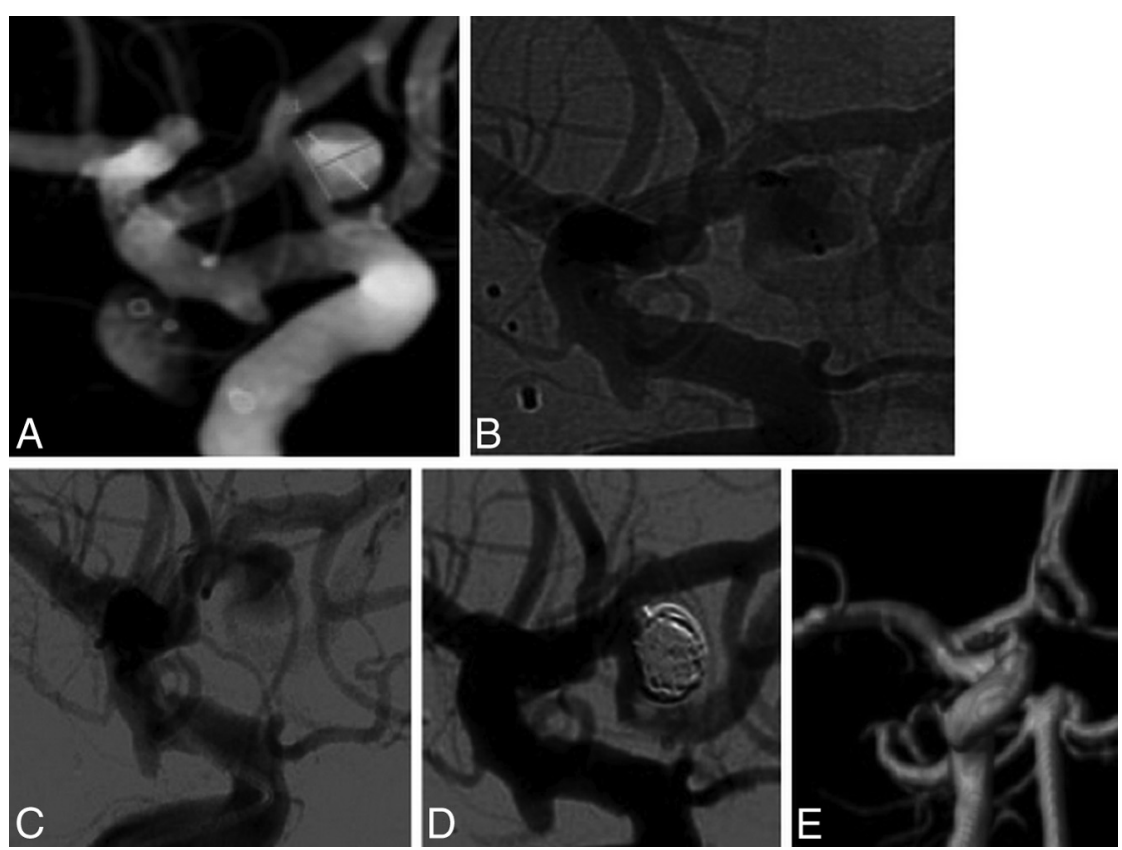

FIG 2. A 54-year-old woman with unruptured anterior communicating artery aneurysm. $A, 3 D$ angiography shows a $4.8-\mathrm{mm}$ wide-neck 6-mm-long anterior communicating artery aneurysm. $B$ and $C$, Unsuccessful deployment of a WEB-DL device occluding the origin of the left anterior cerebral artery. D, Complete aneurysm occlusion after coiling. E, Follow-up MRA at 3 months shows complete occlusion of the anterior communicating artery aneurysm.

rysm neck, a balloon was used to push the WEB inside the aneurysm, and a distal thromboembolic event later occurred in branches of the ipsilateral anterior cerebral artery. At 1 month, the patient had an mRS score of 1 .

\section{Clinical Outcome}

Clinical outcomes are summarized in Table 2. Six (85.7\%) of 7 patients with successful WEB deployment were asymptomatic at 1-month follow-up (mRS 0 ). One patient presented with posttreatment right-sided hemiparesis (patient 2) due to a distal left A2 thromboembolism found later on follow-up MR imaging. At 1 month, the patient recovered most of the deficit with a mild brachial deficit remnant (mRS 1).

No treatment-related mortality was observed $(0.0 \%)$; posttreatment permanent morbidity was $0.0 \%$.

\section{Anatomic Outcome}

At the end of procedure, 6 of the $7 \mathrm{pa}$ tients $(85.7 \%)$ achieved satisfactory occlusion (complete occlusion or neck remnant). Two patients had complete occlusion, and 4 were found to have a neck remnant. All of the 7 patients with successful WEB deployment were assessed at short-term follow-up (3-6 months) by using either conventional angiography (6 cases) or CTA (1 case); satisfactory occlusion was seen in 6 patients $(85.7 \%)$.

\section{Illustrative Cases}

Case 1. A 65-year-old man (patient 7) presented with a $8.2-\mathrm{mm}$ wide-neck anterior communicating artery aneurysm seen at angiography (Fig $1 A,-B$ ). Endovascular treatment with a $7 \times 6 \mathrm{~mm}$ WEB-SL device was performed (Fig $1 C$, $-D)$. Good clinical outcome was recorded after treatment, and a 6-month follow-up angiogram showed complete occlusion of the aneurysm (Fig 1E, $-F$ ).

Case 2. A 54-year-old woman (patient 4) presented with an incidental finding of a 4.8-mm wide-neck anterior communicating artery aneurysm (Fig 2A). Endovascular $6 \times 3 \mathrm{~mm}$ WEB deployment was performed, and postprocedure angiography showed suboptimal positioning of the device with protrusion of its base through the neck of the aneurysm and residual contrast filling of the sac. A second $6 \times 3 \mathrm{~mm}$ WEB-DL was deployed, but control injections again revealed suboptimal positioning (Fig $2 B,-C$ ). A decision was made to coil the aneurysm (Fig 2D), and 3-month MRA follow-up showed complete aneurysm occlusion (Fig 1E). 

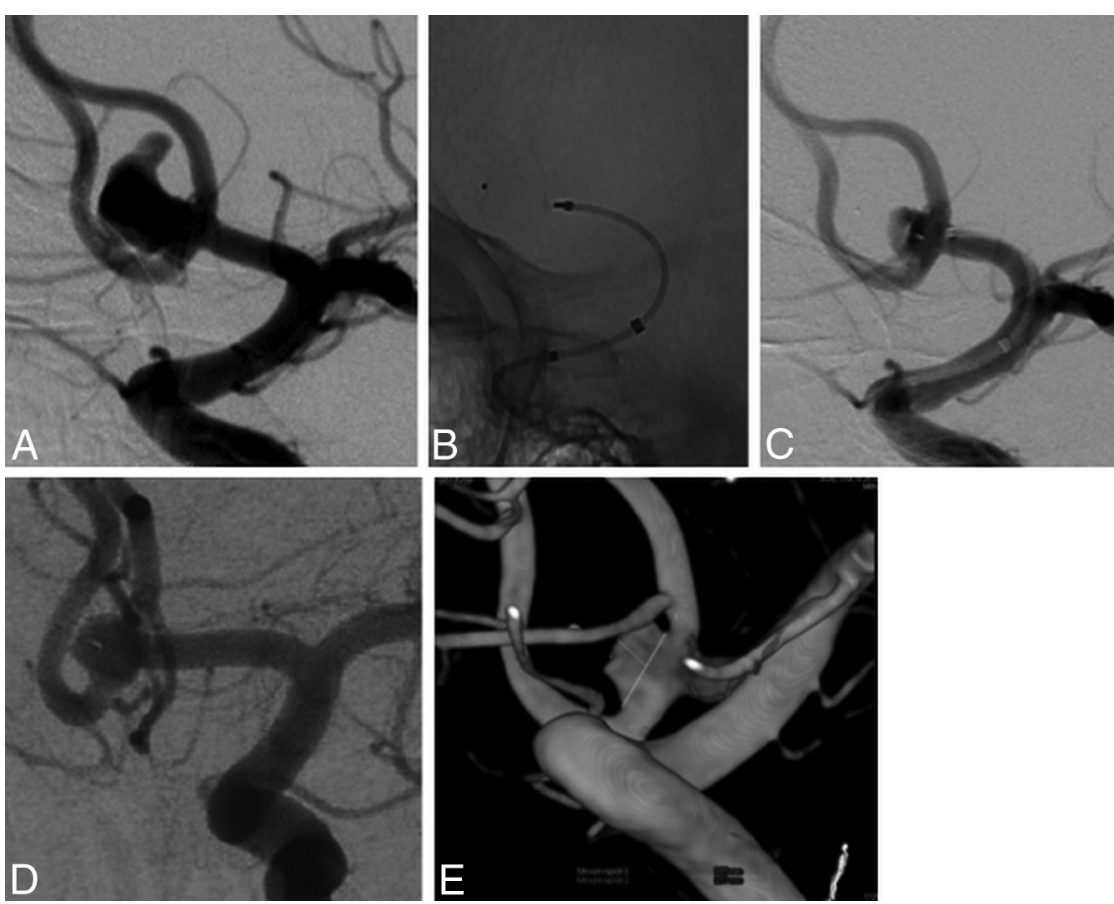

FIG 3. A 46-year-old man with an anterior communicating artery aneurysm. A, Angiography shows a 6-mm wide-neck 8-mm-long anterior communicating artery aneurysm. $B$ and $C, A 7 \times 5$ $\mathrm{mm}$ WEB-SL device is successfully deployed. $D$ and $E$, Six-month follow-up angiography shows a significant neck remnant.

Case 3. A 46-year-old man (patient 10) presented with an incidental anterior communicating artery aneurysm. Angiography revealed a 5.4-mm wide-neck anterior communicating artery aneurysm (Fig $3 A$ ). Endovascular treatment was performed by using a WEB-SL device with final incomplete aneurysm occlusion (Fig $3 B,-C)$. Angiographic follow-up at 6 months revealed incomplete occlusion of the neck (Fig 3D, -E).

\section{DISCUSSION}

This small series shows that endovascular treatment with WEB-DL and WEB-SL devices is feasible in wide-neck anterior communicating artery aneurysms, with very low morbidity and mortality and a high adequate occlusion rate at short-term follow-up.

\section{Feasibility and Patient Selection}

We show that treatment of anterior communicating artery aneurysms with a WEB device is feasible; however, selection of patients should be taken into account before deciding on a WEB treatment. In this series, the rate of failure was not negligible $(30 \%)$. WEB treatment of anterior communicating artery aneurysms requires a favorable angle between the long axis of the aneurysm and that of the parent vessel (A1 segment of the anterior cerebral artery) as reported by Lubicz et al. ${ }^{15}$ An unfavorable anatomy may lead to prolonged interventional timing and/or impossible WEB deployment. We observed 1 deployment failure (patient 4) because the long axis of the aneurysm was not in line with that of the parent vessel, and after several failed attempts to place the microcatheter, it was decided to coil the aneurysm.

In addition, a favorable angle between the centerline of the A1 segment of the anterior cerebral artery and the terminal internal carotid artery is also important (patient 5). The use of a much larger and stiffer microcatheter for the WEB device than usually used for coiling is currently mandatory.

\section{Safety of the WEB Device}

The safety of this device seems very good. In our small series, there was neither device-related mortality nor permanent morbidity, despite the specific anatomy (wide-neck anterior communicating artery aneurysms). Our results compare well with other studies on the WEB device. In the series of Pierot et $\mathrm{al}^{16}$ dealing with 34 middle cerebral artery aneurysms with unfavorable anatomy, the rate of mortality was $0.0 \%$ and morbidity was $3.1 \%$ (1 intraoperative aneurysm rupture with mRS 3 at 1 month follow-up). In the recent large multicenter series of 85 patients, morbidity and mortality at 1 month were $1.3 \%$ and $0.0 \%$, respectively. ${ }^{18}$

Wide-neck intracranial aneurysms can be treated with stent-assisted coiling $^{4,5}$; however, in case of bifurcation aneurysms such as anterior communicating artery aneurysms, the stent placement procedure requires a Y- or X-configuration, which has a high incidence of adverse events and outcomes. ${ }^{11-13}$ Compared with intracranial stent placement, the major advantage of using a WEB device is the absence of antiplatelet therapy. In our series, no antiplatelet premedication was performed except in 1 patient with an iliac artery stent placement. The use of antiplatelet therapy is known to increase the risk of hemorrhagic complications. ${ }^{7,11,13}$ In a survey that included 1517 patients treated with stents, Shapiro et $\mathrm{al}^{7}$ reported an overall procedure complication rate of $19 \%$ and a periprocedural mortality of $2.1 \%$.

Due to the particular anatomy of anterior communicating artery aneurysms, the use of flow diverters should be limited ${ }^{20}$; moreover, the safety of flow diversion should to be assessed in larger series. $^{21,22}$

\section{Efficacy of the WEB Device}

Satisfactory aneurysm occlusion was achieved in most cases $(85.7 \%)$. Our results are close to those of other series; however, to date, few results of the treatment with the WEB-SL device have been published. ${ }^{14-18}$ In Pierot et al, ${ }^{16}$ adequate occlusion (total occlusion or neck remnant) was observed in $83.3 \%$ of 33 treated aneurysms. In Lubicz et al, ${ }^{15}$ in a series of 19 treated wide-neck bifurcations aneurysms, 2 complete occlusions, 15 near-complete occlusions (89.5\% adequate occlusion), and 2 incomplete occlusions were reported at 6-month angiographic follow-up. Similar findings were also reported in the large prospective French series of 85 patients $(92.3 \%) .{ }^{18}$

However, the rate of neck remnants is not negligible, and the concave base of the WEB device could explain these findings. This 
high rate of neck remnants could also be explained by the compaction of the device toward the dome. Further technical improvements may be needed to ameliorate the occlusion caused by the device. Long-term follow-up of these patients is mandatory to verify its efficacy precisely. In addition, the efficacy of the WEBdevice treatment in terms of aneurysm recanalization according to the type used (WEB-DL or WEB-SL) is not well-known; therefore, mid- and long-term follow-up are needed.

The limitations of our study were the small number of patients and a follow-up period that was too short to evaluate the efficacy of the WEB device. However, it is important to have a preliminary evaluation for this new endovascular treatment device for anterior communicating artery aneurysms.

\section{CONCLUSIONS}

In this small series, we found that the WEB device may be a new treatment option for wide-neck bifurcation anterior communicating artery aneurysms. Angiographic findings of the aneurysms and the parent artery are crucial to improve the feasibility of the WEB device. Nevertheless, the rate of neck remnants is not negligible and necessitated improvements of the device technology.

Disclosures: Laurent Pierot-RELATED: Consulting Fee or Honorarium: Sequent Medical; UNRELATED: Consultancy: Codman, Covidien, MicroVention, Balt, Stryker Neurovascular. Xavier Barreau—RELATED: Consulting Fee or Honorarium: Sequent Medical, Comments: honorarium for filling my Web case data base. Denis Herbreteau-RELATED: Consulting Fee or Honorarium: Sequent Medical (proctoring); Support for Travel to Meetings for the Study or Other Purposes: Sequent Medical. Francis Turjman—UNRELATED: Consultancy: Codman. * Balt, Covidien; Payment for Lectures (including service on Speakers Bureaus): Codman, ${ }^{*}$ Covidien*; Payment for Development of Educational Presentations: Codman, Balt*; Travel/Accommodations/Meeting Expenses Unrelated to Activities Listed: Covidien, Codman. *Money paid to the institution.

\section{REFERENCES}

1. Pierot L, Spelle L, Vitry F; for the ATENA Investigators. Immediate clinical outcome of patients harboring unruptured intracranial aneurysms treated by endovascular approach: results of the ATENA study. Stroke 2008;39:2497-504

2. Gory B, Turjman F. Endovascular treatment of 404 intracranial aneurysms treated with Nexus detachable coils: short-term and midterm results from a prospective, consecutive, European multicenter study. Acta Neurochir 2014;156:831-37

3. Gory B, Kessler I, Seizem Nekiri G, et al. Initial experience of intracranial aneurysm embolization using the balloon remodeling technique with Scepter C, a new double-lumen balloon. Interv Neuroradiol 2012;18:284-87

4. Gory B, Klisch J, Bonafé A, et al. Solitaire AB stent-assisted coiling of wide-necked intracranial aneurysms: short-term results from a prospective, consecutive, European multicentric study. Neuroradiology 2013;55:1373-78

5. Gory B, Klisch J, Bonafé A, et al. Solitaire AB stent-assisted coiling of wide-necked intracranial aneurysms: mid-term results from the SOLARE study. Neurosurgery 2014;75:215-19

6. Raymond J, Guilbert F, Weill A, et al. Long-term angiographic recurrences after selective endovascular treatment of aneurysms with detachable coils. Stroke 2003;34:1398-403

7. Shapiro M, Becske T, Sahlein D, et al. Stent-supported aneurysm coiling: a literature survey of treatment and follow-up. AJNR Am J Neuroradiol 2012;33:159-63

8. Spiotta AM, Gupta R, Fiorella D, et al. Mid-term results of endovascular coiling of wide-necked aneurysms using double stents in a $\mathrm{Y}$ configuration. Neurosurgery 2011;69:421-29

9. Jankowitz BT, Thomas A, Jovin T, et al. Y stenting using kissing stents for the treatment of bifurcation aneurysms. J Neurointerv Surg 2012;4:16-21

10. Saatci I, Geyik S, Yavuz K, et al. X-configured stent-assisted coiling in the endovascular treatment of complex anterior communicating artery aneurysms: a novel reconstructive technique. AJNR Am J Neuroradiol 2011;32:E113-17

11. Bartolini B, Blanc R, Pistocchi S, et al. "Y" and "X" stent-assisted coiling of complex and wide-neck intracranial bifurcation aneurysms. AJNR Am J Neuroradiol 2014;35:2153-58

12. Gory B, Rouchaud A, Saleme S, et al. Endovascular treatment of middle cerebral artery aneurysms for 120 nonselected patients: a prospective cohort study. AJNR Am J Neuroradiol 2014;35:715-20

13. Piotin M, Blanc R, Spelle L, et al. Stent-assisted coiling of intracranial aneurysms: clinical and angiographic results in 216 consecutive aneurysms. Stroke 2010;41:110-15

14. Pierot L, Liebig T, Sychra V, et al. Intrasaccular flow-disruption treatment of intracranial aneurysms: preliminary results of a multicenter clinical study. AJNR Am J Neuroradiol 2012;33:1232-38

15. Lubicz B, Mine B, Collignon L, et al. WEB device for endovascular treatment of wide-neck bifurcation aneurysms. AJNR Am J Neuroradiol 2013;34:1209-14

16. Pierot L, Klisch J, Cognard C, et al. Endovascular WEB flow disruption in middle cerebral artery aneurysms: preliminary feasibility, clinical, and anatomical results in a multicenter study. Neurosurgery 2013;73:27-34; discussion 34-35

17. Klisch J, Sychra V, Strasilla C, et al. The Woven EndoBridge cerebral aneurysm embolization device (WEB II): initial clinical experience. Neuroradiology 2011;53:599-607

18. Papagiannaki C, Spelle L, Januel AC, et al. WEB intrasaccular flow disruptor-prospective, multicenter experience in 83 patients with 85 aneurysms. AJNR Am J Neuroradiol 2014;35:2106-11

19. Bonita R, Beaglehole R. Recovery of motor function after stroke. Stroke 1988;19:1497-500

20. Darsaut T, Bing F, Salazkin I, et al. Flow diverters failing to occlude experimental bifurcation or curved sidewall aneurysms: an in vivo study in canines. J Neurosurg 2012;117:37-44

21. Gory B, Bonafé A, Pierot L, et al. Safety and efficacy of flow-diverter stents in endovascular treatment of intracranial aneurysm: interest of the prospective DIVERSION observational study. J Neuroradiol 2014;41:93-96

22. Turjman F, Levrier O, Combaz X, et al. EVIDENCE Trial: design of a phase 2, randomized, controlled, multicenter study comparing flow diversion and traditional endovascular strategy in unruptured saccular wide-necked intracranial aneurysms. Neuroradiology 2015; $57: 49-54$ 